\title{
The effect of the Talking Diabetes consulting skills intervention on glycaemic control and quality of life in children with type 1 diabetes: cluster randomised controlled trial (DEPICTED study)
}

\author{
(c) $\begin{gathered}\text { (1) (8) } \\ \text { ay }\end{gathered}$
}

Mike Robling senior lecturer and associate director ${ }^{1}$, Rachel McNamara senior trial manager ${ }^{1}$, Kristina Bennert senior research fellow ${ }^{1}$, Christopher $C$ Butler professor of primary care medicine and head of department ${ }^{5}$, Sue Channon consultant clinical psychologist ${ }^{2}$, David Cohen professor of health economics ${ }^{3}$, Elizabeth Crowne consultant in paediatric endocrinology and diabetes ${ }^{4}$, Helen Hambly data manager ${ }^{1}$, Kamila Hawthorne reader ${ }^{5}$, Kerenza Hood professor of medical statistics and director ${ }^{1}$, Mirella Longo health economist ${ }^{3}$, Lesley Lowes reader and paediatric diabetes nurse ${ }^{6}$, Tim Pickles junior statistician ${ }^{1}$, Rebecca Playle senior statistician ${ }^{1}$, Stephen Rollnick professor of healthcare communication ${ }^{5}$, Emma Thomas-Jones senior trial manager ${ }^{1}$, John W Gregory professor of paediatric endocrinology and honorary consultant ${ }^{2}$

\footnotetext{
'South East Wales Trials Unit, Department of Primary Care and Public Health, School of Medicine, Cardiff University, Cardiff CF14 4YS, UK; ${ }^{2}$ Department of Child Health, School of Medicine, Cardiff University; ${ }^{3}$ Faculty of Health, Sport and Science, University of Glamorgan, UK; ${ }^{4}$ Bristol Royal Hospital for Children, University Hospital Bristol NHS Foundation Trust, UK; ${ }^{5}$ Department of Primary Care and Public Health, School of Medicine, Cardiff University; ${ }^{6}$ School of Nursing and Midwifery Studies, Cardiff University
}

\begin{abstract}
Objective To evaluate the effectiveness on glycaemic control of a training programme in consultation skills for paediatric diabetes teams.

Design Pragmatic cluster randomised controlled trial.

Setting 26 UK secondary and tertiary care paediatric diabetes services.

Participants 79 healthcare practitioners (13 teams) trained in the intervention (359 young people with type 1 diabetes aged 4-15 years and their main carers) and 13 teams allocated to the control group (334 children and their main carers).

Intervention Talking Diabetes programme, which promotes shared agenda setting and guiding communication style, through flexible menu of consultation strategies to support patient led behaviour change.

Main outcome measures The primary outcome was glycated haemoglobin $\left(\mathrm{HbA}_{1 \mathrm{c}}\right)$ level one year after training. Secondary outcomes were clinical measures (hypoglycaemic episodes, body mass index, insulin regimen), general and diabetes specific quality of life, self reported and proxy reported self care and enablement, perceptions of the diabetes
\end{abstract}

team, self reported and carer reported importance of, and confidence in, undertaking diabetes self management measured over one year. Analysis was by intention to treat. An integrated process evaluation included audio recording a sample of 86 routine consultations to assess skills shortly after training (intervention group) and at one year follow-up (intervention and control group). Two key domains of skill assessment were use of the guiding communication style and shared agenda setting.

Results 660/693 patients (95.2\%) provided blood samples at follow-up. Training diabetes care teams had no effect on $\mathrm{HbA}_{1 \mathrm{c}}$ levels (intervention effect 0.01 , 95\% confidence interval -0.02 to $0.04, P=0.5$ ), even after adjusting for age and sex of the participants. At follow-up, trained staff $(n=29)$ were more capable than controls $(n=29)$ in guiding (difference in means 1.14, $\mathrm{P}<0.001$ ) and agenda setting (difference in proportions $0.45,95 \%$ confidence interval 0.22 to 0.62 ). Although skills waned over time for the trained practitioners, the reduction was not significant for either guiding (difference in means $-0.33, \mathrm{P}=0.128$ ) or use of agenda setting (difference in proportions $-0.20,-0.42$ to 0.05 ). 390 patients (56\%) and 441 carers (64\%) completed follow-up questionnaires. Some 
aspects of diabetes specific quality of life improved in controls: reduced problems with treatment barriers (mean difference $-4.6,95 \%$ confidence interval -8.5 to $-0.6, P=0.03)$ and with treatment adherence $(-3.1,-6.3$ to $-0.01, P=0.05)$. Short term ability to cope with diabetes increased in patients in intervention clinics $(10.4,0.5$ to $20.4, P=0.04)$. Carers in the intervention arm reported greater excitement about clinic visits (1.9, 1.05 to $3.43, P=0.03)$ and improved continuity of care $(0.2,0.1$ to $0.3, P=0.01)$.

Conclusions Improving glycaemic control in children attending specialist diabetes clinics may not be possible through brief, team-wide training in consultation skills.

Trial registration Current Controlled Trials ISRCTN61568050.

\section{Introduction}

Diabetes is the third most common chronic disease in childhood, with at least 13.5 new cases per 100000 children annually in the United Kingdom. ${ }^{12}$ The control of blood glucose is an important risk factor for complications ${ }^{3}$ and is affected by insulin treatment, lifestyle, and psychosocial and educational influences. ${ }^{4}$ However, management targets are realised in only a small proportion of children. ${ }^{5}$ Psychoeducational interventions, including education integrated into routine care and continued parental involvement that encourages self efficacy in adolescents have resulted in modest improvements in blood glucose control in young people with diabetes. ${ }^{7-9}$ Current evidence is predominantly available from the United States and may be context dependent. There is also little evidence about the effect of psychosocial or educational interventions involving younger children. Furthermore, although trials have shown some recent methodological improvements, most have been underpowered to detect clinically important changes in glycated haemoglobin $\left(\mathrm{HbA}_{1 \mathrm{c}}\right)$ levels. ${ }^{78}$ Evidence from the United Kingdom on the effectiveness of psychoeducational interventions alone in improving glycaemic control in children is limited. ${ }^{9}$ The authors of a systematic review concluded that although there was some evidence that theoretically based interventions are more effective, many interventions evaluated so far have not been explicitly theory based. ${ }^{70}$

\section{Although clear evidence for the superiority of one}

psychoeducational approach over another is lacking, an efficacy study of motivational interviewing in childhood diabetes ${ }^{9}$ found a beneficial effect on $\mathrm{HbA}_{1 \mathrm{c}}$ levels. Motivational interviewing promotes prioritising patient preference and supports patient autonomy. It is, however, unclear whether large numbers of practitioners delivering this intervention in a routine clinical setting (as opposed to delivery by specialist therapists) is effective. ${ }^{112}$

The delivery of diabetes care to children in the United Kingdom is usually located in secondary care and the multidisciplinary teams include paediatricians with expertise in childhood diabetes, nurse specialists, dietitians, child psychologists, podiatrists, and social workers. Only $21 \%$ of services, however, report integrated specialist psychologist support. ${ }^{13}$ Therefore the responsibility of psychoeducational support for affected children and their families most often remains with other members of the healthcare team. Evidence to inform decisions about whether to invest in a limited number of specialist psychoeducational practitioners or to train whole teams in psychoeducational consulting skills is lacking. The whole team approach has the benefit of increasing reach, whereas the intensity offered by specialist practitioners may enhance effectiveness but for fewer patients.

Therefore an important gap in the evidence base supporting diabetes care in children was the question of the effectiveness of broadly applicable, theoretically based, team wide training in psychoeducational consulting skills that encourages parental involvement and that promotes self efficacy in adolescents. Given this lack of evidence, we carried out a phase of intervention development and feasibility assessment. This showed that practitioners in UK secondary care paediatric diabetes teams recognised the importance of dealing with psychosocial needs but lacked the confidence and training in consultation skills to address them. ${ }^{14}{ }^{15}$ Practitioners reported challenges in engaging families in the process of care and that available training was remote from actual clinical practice. ${ }^{16}$ Family members of affected children reported feeling that attendance at a clinic seemed to serve the needs of clinicians rather than those of the children and their parents and sometimes marginalised the children themselves. ${ }^{17}$ Children and teenagers with diabetes indicated that they wanted a more positive approach from teams, which took greater account of the constraints of their life world. Our research team hosted a series of developmental workshops to integrate findings from reviews of the evidence base with perspectives from lay and professional stakeholders: the Stakeholder Advisory Group. ${ }^{18}$

The Talking Diabetes training programme was developed from this process. It focused on shared setting of agendas and a flexible style of communication by practitioners. The programme was informed by motivational interviewing and promoted a guiding consulting style to explore and support opportunities to change health related behaviours, which may lead to improved metabolic control. The programme provided a menu of consultation strategies, and practitioners were trained to use it through a combination of web based training and two workshops. We evaluated the effectiveness of training teams using the Talking Diabetes programme in improving glycaemic control and the quality of life of young people with diabetes. We hypothesised that practitioners trained using the programme would support young people to manage their diabetes better resulting in a lower mean $\mathrm{HbA}_{1 \mathrm{c}}$ level than in young people cared for by untrained teams.

\section{Methods}

We present a pragmatic, cluster randomised controlled trial of the Talking Diabetes programme within UK clinical practice. The methods have been described in detail previously. ${ }^{19}$ Briefly, the evaluation phase of the Talking Diabetes training programme, known as the DEPICTED (the Development and Evaluation of a Psychosocial Intervention in Children and Teenagers Experiencing Diabetes) study was set in UK secondary care. An economic analysis was carried out alongside the trial and is reported elsewhere. ${ }^{20}$

\section{Centres and participants}

Centres were identified and approached during the development phase of the study using an augmented specialist register of UK services. ${ }^{15}$ Of the centres expressing an interest, 30 were invited to participate based on entry criteria (minimum eligible clinic list size of 40, at least one paediatrician with an interest in diabetes, and a diabetes specialist nurse). Families were eligible for participation if their child had type 1 diabetes diagnosed no less than 12 months earlier, was aged between 4 and 15 years, was not expected to leave the care of the participating centre for the duration of the study, and if both child and one parent or carer were able to complete study materials and provide adequate informed consent. Children were not eligible if they were not being looked after by either their parent or their guardian, had a comorbidity that was likely to affect their $\mathrm{HbA}_{\mathrm{lc}}$ measurement, were in receipt of psychiatric or psychological 
therapy, or were clinically judged to be vulnerable owing to social circumstances or an existing medical condition.

\section{Recruitment and centre randomisation}

A locally employed research nurse identified and approached eligible families before randomisation by centre. For each centre, a random sample of 40 children was selected by the trial team using anonymised clinic lists with the aim of obtaining 30 recruited children. Families were approached by letter and recruited after written informed consent from both parent and child (assent in the case of younger patients). Recruitment and randomisation were undertaken in three blocks but with patients in each centre being approached en bloc by letter. ${ }^{21}$ Each participating centre was allocated to undertake training in the Talking Diabetes programme either before (intervention group) or at the end (control group) of a one year study period.

Randomisation was optimally balanced for patient list size. ${ }^{22}$ The first block of centres recruited was randomised so that intervention training could begin. Subsequent blocks of centres were randomised, maintaining the balance for list size. The trial statistician carried out randomisation independent of centre and child recruitment. A statistician independent of the trials unit allocated the intervention and control centres to the final sequence. The allocations were then passed to the trial manager and concealed from centres until training was arranged for intervention centres.

\section{Intervention}

The training programme aimed to prepare practitioners for more constructive consultations about behaviour change by placing patients at the centre of their own consultation and enhancing engagement with their own healthcare. ${ }^{19}$ Training emphasised shared setting of agendas and a guiding communication style, as well as discrete strategies and skills drawn from motivational interviewing practice. Role played interactions modelled how the strategies could be flexibly deployed in routine consultations. ${ }^{23}{ }^{24}$ The shared agenda setting was supported by a physical tool (3T: TimeToTalk, produced by Cardiff University), which was a pad of sheets with images of young people and encircled discussion topics including adequate blank space and empty circles for the young people and their carers to record and review agenda items with clinic staff. Training of practitioners was delivered through web based modules, which comprised formal didactic content (about 1.5 hours) and interactive components. Additionally, two team based day workshops, delivered about two weeks apart by two trainers, provided opportunities to review and practice intervention strategies and skills. After the second workshop, practitioners were able to report consultations online and to receive feedback from the trainer team. The bespoke and manualised training programme was constructed around three case studies representing common clinical challenges in paediatric diabetes care. Once trained, practitioners were expected to conduct modified consultations with their patients for the remainder of the 12 month study period, as part of otherwise routine care.

\section{Primary and secondary outcomes (measured at patient level)}

The primary outcome measure was $\mathrm{HbA}_{\mathrm{lc}}$ level measured at baseline and at one year using capillary blood samples collected by local research nurses and assayed at a single central laboratory. Values were reported after adjustment against the Diabetes Control and Complications Trial (DCCT) international standard. Secondary patient reported outcomes included diabetes specific quality of life, patient enablement, perceptions of the diabetes team, and self care. ${ }^{25-30}$ (See supplementary table on bmj.com for details of secondary outcomes.) Secondary carer reported outcomes included diabetes specific quality of life and enablement and perceptions of the diabetes team. Parent reported proxy measures (for children under 11 years) included diabetes specific quality of life and self care. Novel single item measures of clinic related affect (for example, feeling fed up, excited, guilty, good, worried) were also included in carer and all patient questionnaires. Effective behaviour change can be viewed as the combined effect of the importance attached to changing a behaviour and the confidence of an individual to achieve such change. ${ }^{31}$ Therefore we developed two new six item scaled measures of importance and confidence in managing diabetes and evaluated these for inclusion as outcomes for older children ( $\geq 11$ years) and carers.

At baseline, questionnaires were handed to families for completion and returned direct to the trial team by post. Follow-up questionnaires were dispatched and returned by post directly to the trial team. An interim questionnaire assessing enablement was also completed at the first clinic visit after the start of the trial. A case report form recording demographic and clinical data (including hypoglycaemic episodes, body mass index, and insulin regimen) was completed at baseline by the research nurse from the young people's notes. Clinical data were collected at each subsequent clinic visit up to and including the one year follow-up visit.

\section{Sample size}

An individually randomised trial would require 200 young people to detect a moderate effect size of 0.4 for $\mathrm{HbA}_{1 \mathrm{c}}$ at a $5 \%$ significance level with $80 \%$ power. Assuming an intracluster correlation coefficient of 0.08 (based on audit data from the Wales Paediatric Diabetes Interest Group) and 24 centres recruiting an average of 23 young people resulted in the sample size being inflated to 550. Adjusting this to account for a $22 \%$ loss to follow-up resulted in a target of 700 recruited young people. Of the 30 centres invited, four did not participate owing to a withdrawal of interest or inability to complete agreements in time. The target number of centres was finally increased by two (to 26) to allow for withdrawal of centres.

\section{Statistical analysis}

The primary analysis was by intention to treat, comparing $\mathrm{HbA}_{1 \mathrm{c}}$ values between study groups at one year follow-up. The distribution of $\mathrm{HbA}_{1 \mathrm{c}}$ data was positively skewed and a natural $\log$ transformation performed for regression analysis. Multilevel modelling was adjusted for cluster (centre) and individual effects. Baseline levels of $\mathrm{HbA}_{\mathrm{lc}}$ were included as a covariate. Primary analysis involved a two level linear model and included interaction terms for both age and sex with treatment allocation. The influence of missing data was examined by replacing missing trial $\mathrm{HbA}_{1 \mathrm{c}}$ values with routine clinic values where possible. Analysis of secondary outcomes also used multilevel modelling and incorporated baseline scores as covariates. Variations in the skewness of outcome data were all within limits of the methods used, and scores remained untransformed for modelling. No interim analyses were planned or undertaken.

\section{Process evaluation}

The process evaluation focused on two substantive components: the adequacy of training delivery and fidelity to the menu of guiding skills and strategies. The adequacy of training involved assessing level and quality of engagement by practitioners with 
the training materials (access to online learning modules, attendance at the two workshops, and provision of clinical case feedback to trainers after training). The guiding skills and strategies component involved rating a sample of audio recorded clinical consultations across the trial sites. In addition, representatives of each intervention arm clinical team were interviewed by telephone at the end of the study period to determine how the intervention was received by teams (including factors that were seen to hinder or facilitate implementation), and perceptions of the impact of training on practitioner performance. Transcribed data from the semistructured interviews were subject to coding and inductive analysis led by one member of the research team (ETJ), with additional input from two other experienced social researchers. The results of the interview study are fully reported elsewhere, and are summarised here. ${ }^{20}$

Audio recording routine consultations enabled assessment of the practitioners' performance using an adapted measurement scale. ${ }^{19}{ }^{20}$ Items assessed performance across five domains: overall adherence to guiding style, agenda setting, and each of the three consultation strategies (exploring the pros and cons of change, importance and confidence about making changes, and brainstorming). Items from an existing measure of motivational interviewing practice were supplemented with those dealing with intervention specific content. ${ }^{32}$ Recordings were collected from intervention group practitioners immediately after training and at one year, and from control group practitioners before training at the end of the one year study. Practitioners were asked to record all consultations within a single clinical session (where consent could be obtained) and to nominate two consultations where a behaviour change issue was discussed (although analysis could have included any consultation in that session). To collect recordings we randomly selected a maximum of three practitioners per clinic. Where available, two consultations per practitioner were selected at random for further analysis (two recordings per practitioner, per time point for the intervention group). All recordings selected were scored by a single trained rater and one in four additionally rated by a second rater. Raters were blinded to treatment allocation, based with the trial team, and unfamiliar to the practitioners whose consultations were being assessed. Where practitioner recordings were rated by two raters, $\kappa$ statistics were used to assess reliability and were between 0.49 and 0.88 for 10 of the 12 scales rated (indicating moderate to excellent agreement) but lower for shared agenda setting use and skilfulness ( 0.27 and 0.30 , respectively).

\section{Results}

Twenty six centres participated and recruited 693 young people with type 1 diabetes between August 2007 and January 2008 (figure $\Downarrow$ ). Table $1 \Downarrow$ shows the baseline characteristics of the participants by study allocation. Although more intervention centres than control centres reached their recruitment targets, the characteristics were adequately balanced across arms, including $\mathrm{HbA}_{1 \mathrm{c}}$ levels. Adjusting for sex in the primary analysis to account for the slight excess of boys in the intervention arm did not alter the results. To reduce bias from knowledge of allocation, recruitment was attempted before revealing the centre allocation and was achieved for 213 patients (30.7\%). No evidence of bias was found when baseline data were compared between groups recruited before and after revealing treatment allocation.
Seventy nine practitioners received training across the 13 intervention centres and reported enthusiasm for the training package (including online and workshops). ${ }^{20}$

\section{Primary outcome}

Baseline $\mathrm{HbA}_{1 \mathrm{c}}$ measurements were obtained from 356/359 $(99.2 \%)$ young people in the intervention arm and 333/334 $(99.7 \%)$ in the control arm and from $342(95.3 \%)$ and 318 $(95.2 \%)$ respectively at follow-up. $\mathrm{HbA}_{\mathrm{lc}}$ levels increased in both groups during the study period. The mean (SD) $\mathrm{HbA}_{1 \mathrm{c}}$ for the control group was 9.5 (1.7) and for the intervention group was 9.7 (1.7) at follow-up. The intervention effect adjusted for baseline $\mathrm{HbA}_{1 \mathrm{c}}$ level (log transformed data) was 0.01 (95\% confidence interval -0.02 to $0.04, \mathrm{P}=0.50$, intraclass correlation coefficient 0.057 ) and was not significant. Adding values from routine clinic data for missing outcome data did not alter the result (missing data were only evident for three young people in the control group and seven in the intervention group). Sex was significantly associated with $\mathrm{HbA}_{1 \mathrm{c}}$ level at follow-up, but adjusting for age and sex did not alter the results and no significant interactions were evident between treatment allocation and age or sex.

\section{Patient and carer secondary outcomes}

Overall, 390 young people (56\%) and 441 carers (64\%) completed follow-up questionnaires at 12 months (figure). Among the young people there was no intervention effect on perceptions of the team providing healthcare (table $2 \Downarrow$ ). Of the quality of life subscales, the control group showed a small improvement in problems with treatment barriers and a borderline improvement in problems with treatment, which was not found for the intervention group (table 2). No other differences were evident in standardised secondary outcomes for the young people at 12 months (tables 2 and $3 \Downarrow$ ). Enablement scores were higher for intervention patients in the short-term, but this advantage was not sustained to 12 months (table 2). Two six item measures of importance and confidence in diabetes self management developed for the study showed adequate construct validity at baseline (factor analysis showing a single factor solution in each case, and Cronbach's $\alpha$ above 0.84 for both patient and carer versions). No significant intervention effect was found for either measure (table 2).

Among carers, there was no evidence of an intervention effect on perceptions of the healthcare team, or on any of the quality of life subscale scores (table $4 \Downarrow$ ). A significant intervention effect was found on perceptions of continuity of care with improvements for the intervention group and deterioration for the control group (table 4). Carers in the intervention group felt more excited about prospective visits to the clinic (table $5 \Downarrow$ ), but no other differences were shown between the study groups on the standardised or newly derived outcome measures (tables 4 and 5).

\section{Safety of treatment and clinical outcomes}

No reports of serious adverse events reported to the trial team were judged to be related to the intervention. The intervention had no effect on hypo episodes, body mass index, or insulin regimen.

\section{Process evaluation}

Across the 13 clinical teams in the intervention arm of the study, 75 practitioners were eligible to be trained at study baseline. Of these, $71(94.7 \%)$ attended one or both of the workshops and all logged onto the online training. After the start of the study 
period, a further four practitioners began working within one of the 13 centres, and all made attempts to access the online training at some point. The mean (SD) duration of time spent logged onto the web site by each practitioner was 217 minutes (137 minutes). After the second workshop, 43 practitioners provided either partial or full reporting of clinical case data to the training team for feedback.

In total, 170 valid recordings of consultations were obtained (19 clinicians from 10 of the 13 intervention centres provided data immediately after training, 30 clinicians from 13 of the 26 trial centres returned useable data at the one year follow-up). At one year, the intervention group practitioners had better scores for guiding style (general style, evocation, collaboration, and autonomy-supportive) than did the control group practitioners (table $6 \Downarrow$ ). For the intervention group, guiding style scores decreased over time, but this difference was only significant for evocation (table 6). At one year, agenda setting and brainstorming were more commonly observed in the intervention group than were pros and cons or importance and confidence (table $7 \Downarrow$ ). The skilfulness by which these were applied by intervention practitioners did not significantly alter over time (table $8 \Downarrow$ ).

The times patients and carers reported that they spent either individually (parent only or child only) or together with various health professionals at the clinic was recorded on case report forms. The mean (SD) reported total time was 99.92 (56.30) minutes for intervention clinics and 104.79 (69.60) minutes for control clinics. The difference was not significant $(\mathrm{P}=0.32)$. During the trial period, $11 / 334$ (3.3\%) young people in the control arm did not attend the clinic at all compared with 4/359 $(1.1 \%)$ in the intervention arm (difference $2.2,95 \%$ confidence interval -0.1 to 4.8 ). The mean (SD) number of clinic visits was 3.5 (1.1) for participants in both the intervention and the control arm. To investigate possible dose-effect, the number of clinic visits was added to the multilevel model for the primary outcome. The number of visits was not statistically significant and the interaction between number of visits and trial arm was not significant.

Eleven nurses, one dietitian, and one doctor from the intervention centres were interviewed. Results of the main interview analysis are reported elsewhere. ${ }^{20}$ The following key observations were, however, reported by interviewees. The agenda setting tool was variably used by clinical teams, some of whom sent it out to patients in advance of attending the clinic, some making it available on arrival or in the actual consultation. Respondents reported a reduction in use over time, perhaps because issues may have already been raised and tackled in previous consultations, although several teams reported continued attempts to use the principle of a shared agenda setting approach. Interviewees positively appraised the training and valued the whole team approach. Facilitators of implementation included a physical aide memoire of the menu of strategies and opportunities that were taken by some teams for team based reflection. Barriers included the perceived time required to practice and master intervention skills and time constraints associated with busy clinics. However, many interviewees reported confidence in their ability to implement new skills over time. Staff turnover was also reported to be a barrier to effective implementation. Despite such barriers, most interviewees considered that consultations had shifted away from clinical outcomes towards the needs of the child, facilitated by a structured but open consultation with a less directive approach. Many felt that their practise had changed but with variable levels of skilfulness.

\section{Discussion}

This multicentre, pragmatic trial evaluated the effectiveness of a complex psychoeducational consulting skills intervention, which aimed to enable all clinical members of paediatric diabetes care teams to facilitate improved metabolic control in their patients. We found that training paediatric teams in the Talking Diabetes intervention did not improve glycaemic control, had a negative impact on some aspects of quality of life in the young people one year after practitioner training, but had a short term beneficial effect on coping. The theory based intervention was developed with a high level of stakeholder input and included agenda setting and the flexible use of consultation styles with a greater focus on the "guiding" style along with other strategies drawn from motivational interviewing, ${ }^{33}$ and aimed to improve psychoeducational consultation skills and practice in all members of the care team. Some benefits of the intervention on perceived continuity of care and feeling excited about clinic visits were observed in carers, but similar improvements were not seen in the children. Whereas these represent secondary outcomes in this study, the former findings are welcome given concerns expressed by parents during intervention development about feeling marginalised during clinic visits.

\section{Strengths and weaknesses of the study}

Intervention development included systematic review of evidence supporting effective psychoeducational interventions in managing childhood diabetes and incorporated viewpoints of practitioners, children, and their families, including the view that clinicians should give prominence to patient preferences and enhance patient autonomy. Principles from motivational interviewing, with a strong evidence base for influencing behaviour change including within diabetes care, informed consultation strategies. ${ }^{91134}$ Presentation of the evolving intervention to a Stakeholder Advisory Group resulted in important modifications, including the development of the agenda setting tool. ${ }^{18}$

The cluster trial design was appropriate to an evaluation of a whole team consultation skills intervention where diffusion of skills at a team level would have been welcomed. Once trained in new consulting skills, clinicians cannot switch between using them and not using them as would have been required with individual patient randomisation. Also, the intervention sought to determine the effect of a consultation skills approach deployed over time by a particular service, so that exposure to a trained team was necessary each time patients consulted. The delivery of the intervention in each centre by a number of practitioners also reduced the possibility that outcomes were a consequence of practitioner influences such as personality, independent of training in the intervention. Ascertainment of the primary trial outcome was virtually complete, ensuring that the study had adequate power to detect a meaningful effect on glycaemic control, and minimised risk of attrition bias.

Trial centres were geographically spread and were balanced for list size in randomisation, providing good generalisability of the results for young people with diabetes aged 4-16 years and their carers in the United Kingdom. The low dropout rate and spread of attendance noted (from zero to six visits during the study period in both trial arms) also strengthens the study findings. There was moderate variation in $\mathrm{HbA}_{1 \mathrm{c}}$ levels between centres at follow-up (intracluster correlation coefficient of 0.06), which is likely to reflect a combination of demographic, clinical, and therapeutic factors differing across sites. Centre and individual level effect were accounted for in the multilevel 
modelling analysis. We also investigated differential effects of the intervention for differing baseline $\mathrm{HbA}_{\mathrm{cc}}$ values. ${ }^{20}$ However, the relevant interaction term was non-significant suggesting that the intervention effect did not vary by initial level of glycaemic control.

Although the practitioners skill levels after training were greater in the intervention centres than in the control centres, the absolute levels achieved were disappointing when compared with the theoretically derived scale endpoints (with average scores for those recently trained just below the scale mid-point). A competency assessment for practitioners after training may have ensured greater fidelity to the delivery of the intervention but would have been difficult to implement. Furthermore, performance diminished over time, suggesting that reinforcement of training was required. Training aimed to enhance consulting skills but not meaningfully increase the duration of consultations. Coverage of trained practitioners by consultation recordings was lower than expected, although was much better at follow-up than at baseline for the intervention group. This was the combined result of practical challenges of collecting audio data in busy routine clinics, requirements for adequately documented consent, technical difficulties in capturing and transferring digital audio, and probably some natural reticence of the practitioners about being recorded. This could therefore have introduced some ascertainment bias into the dataset, although the subsequent selection process for analysis sought to minimise any further selection bias. Although it is possible that the more confident and skilful practitioners were also more likely to provide recordings and hence over-estimate the training effect, evidence of such an effect is still provided.

While the process evaluation confirmed no increase in consultation length, a potentially negative consequence was only brief exposure of child and family to trained clinicians during the year of follow-up (generally three to four clinic visits per year with a total contact time with all practitioners of less than an hour). This was typically less than in previous trials of motivational interviewing and other psychoeducational interventions. For example, in a study in 2007, mean contact time was four sessions of about 45 minutes each, involving the same practitioner and carried out independently from the diabetes clinic. ${ }^{9}$

Most of the practitioners initially identified within each intervention arm team received some or all of the blended training. Once trained, it proved harder for the trainers to directly engage with practitioners to reinforce good practice as planned. Changes to team staff over time probably decreased the potential impact of training, and although web based training remained available for the duration of the study, additional face to face workshops were not usually feasible for incoming staff. Teams varied in their approach to integrating the intervention within their clinic setting and some showed considerable enthusiasm and engagement in developing local ownership. Although the research team and trainers provided generic guidance and tools to support implementation, delivering a low resource intervention that could thus be rolled out more broadly in routine clinics placed restrictions on what could have been otherwise achieved.

The primary trial outcome was chosen as an objective global indicator of disease management with established associations with longer term complications. It also has strong clinical validity for practitioners, parents, and children. It is nevertheless a distal outcome for an intervention that is delivered to practitioners and mediated through clinical consultations, aiming to change patients' attitudes and behaviour. Furthermore, with a consultation agenda that was shared between practitioner and child, not all changes in behaviour that may have been discussed would have been expected to have had either an immediate or even a potential impact on glycaemic control. We therefore placed some emphasis on the importance of quality of life as a key secondary outcome in this trial, and expect that such outcomes will increasingly feature as primary outcomes in the future trials of similar interventions for complex behaviour change.

Building on evidence that outcomes for young people with diabetes are better where parents remain involved in a negotiated manner in their child's care, the training programme produced an intervention that aimed to influence both the children and their carers. ${ }^{35}$ It is of interest that parents in the intervention arm reported greater continuity of care than those in the control arm and did not report reduced confidence in their ability to manage the illness as reported by their children. Parents may have benefitted more from the intervention than their children and might be better placed to provide ongoing support to their children as a consequence of care by teams exposed to the intervention.

\section{Comparison with other studies}

Systematic reviews of psychoeducational interventions in children and adolescents with diabetes report a modest beneficial effect on psychological and metabolic outcomes, ${ }^{736}$ although few interventions have targeted younger children. ${ }^{12}$ A further concern has been the lack of UK based studies, limited data on cost effectiveness, and the use of diabetes specific interventions, which have been poorly described, all making replicability and applicability difficult to assess. ${ }^{78}$ Most interventions have been multifaceted making it difficult to identify which aspects have been most responsible for change. The studies included in the review were often short term, underpowered, not pragmatic, and with interventions delivered by specialists within teams rather than by whole team approaches. It is possible that the effect of the Talking Diabetes intervention will be seen on metabolic control in children after one year (the follow-up period in our study), and that psychosocial and quality of life outcomes are more proximal effects. Some studies of motivational interviewing in diabetes have found positive effects two years after the start of the intervention (for example ${ }^{9}$ ). However, the intervention effect at two years described in the previous study was preceded by a similar advantage at one year, unlike the present study. This comparison therefore does not support a search for longer term benefits of the Talking Diabetes intervention. It nevertheless remains possible that the short term benefit in coping and the longer term negative impact on health related aspects of diabetes quality of life may indicate some longer term impact of the intervention, but further investigation would be required into potential mechanisms.

Our study attempted to tackle these limitations by delivering a theoretically driven, manualised intervention for use by a range of practitioners dealing with a wide age range of children, using clearly defined theoretical principles and strategies, with patient related outcomes assessed one year after training practitioners. Our study therefore differed from the efficacy study of motivational interviewing in childhood diabetes in that it involved training whole teams to deliver the intervention within routine clinical care rather than evaluating an intervention delivered by a single specialist practitioner. ${ }^{9}{ }^{11}$ Furthermore, to make the intervention broadly deliverable in a routine clinic setting, its content was drawn from, but did not fully equate to, motivational interviewing. The added value of incorporating 
reflective listening into the existing programme menu of guiding skills and strategies remains undetermined.

\section{Implications for research and practice}

Although welcomed by practitioners, our findings suggest that training in psychoeducational consultation skills for whole teams does not improve glycaemic control in young people with diabetes over one year. In the light of this new evidence therefore, such training in its current format should not be rolled out in the UK National Health Service. The economic evaluation undertaken within the present study ${ }^{20}$ compared whole team training with no training but did not explore whether whole team training was more cost effective than additional specialist provision. While our finding of no effect on glycaemic control suggests that this is unlikely to be the case, the scarcity of trained clinical psychologists in UK paediatric diabetes services suggests a need for further research to examine whether modified versions of the training intervention-for example, by incorporating a reflective listening component-could improve its clinical and cost effectiveness. ${ }^{37}$

We thank the contribution of the following in the conduct and delivery of the DEPICTED study: Participating clinical centres and support groups: the local principal investigators, members of each clinical team, and local UKCRN research staff participating in the 26 trial centres, and to all the practitioners and families who contributed to the development and implementation of the Talking Diabetes intervention (particularly from clinics and support groups in South Wales and South West England). The local principal investigators and participating NHS Trusts were: Paul Langridge (children's community specialist nurse) at Countess of Chester Hospital NHS Foundation Trust; Tracy Tinklin (consultant paediatrician) at Derby Hospitals NHS Foundation Trust; Francesca Annan (specialist paediatric dietitian) at Royal Liverpool Children's NHS Trust; Timothy Barratt (professor of paediatrics) at Wellcome Trust Clinical Research Facility at Birmingham Children's Hospital NHS Trust; Claire Smith (consultant paediatrician) at East Lancashire Hospitals NHS Trust; Fiona Regan (consultant paediatrician) at the Hillingdon Hospital NHS Trust; Rakesh Amin (consultant paediatric endocrinologist) at Central Manchester and Manchester Children's University Hospitals NHS Foundation Trust; Mark Bone (paediatric diabetologist) at Central Manchester and Manchester Children's University Hospitals NHS Trust; Loretta Davis-Reynolds (consultant paediatrician) and Sunil Bhimsaria (consultant paediatrician) at Barnsley Hospital NHS Foundation Trust; Marie Marshall (paediatric diabetes nurse) at Central Manchester and Manchester Children's University Hospitals NHS Foundation Trust; Neil Hopper (consultant paediatrician) at City Hospitals Sunderland NHS Foundation Trust; Anuja Natarajan (consultant paediatrician) at Doncaster and Bassetlaw Hospitals NHS Foundation Trust; Peter Stutchfield (consultant paediatrician) at Conway and Denbighshire NHS Trust; Jerry Wales (senior lecturer in paediatric endocrinology) at Sheffield Children's NHS Trust; Fran Ackland (consultant paediatrician) at Northampton General Hospital NHS Trust; Shailini Bahl (consultant paediatrician) at Ashford and St Peter's Hospitals NHS Trust; Sue Courtman (diabetes nurse) at East and North Hertfordshire NHS Trust; Ivor Lewis (consultant paediatrician) at Surrey and Sussex Healthcare NHS Trust; Roma Romano-Morgan (paediatric diabetes nurse specialist) at the Whittington Hospital NHS Trust; Joanna Stanley (consultant paediatrician) at the Lewisham Hospital NHS Trust; Victoria Surrell (diabetes specialist nurse) at Hinchingbrooke Healthcare NHS Trust; Tim Taylor (consultant paediatrician) at Royal West Sussex NHS Trust; Nicola Trevelyan (consultant paediatrician) at Southampton University Hospitals NHS Trust; Tabitha Randell (consultant in paediatric endocrinology and diabetes) at Nottingham University Hospitals NHS Trust; Fiona Campbell (clinical director) at the Leeds Teaching Hospitals NHS Trust; Roby Mathew (consultant paediatrician) at Chesterfield
Royal Hospital NHS Foundation Trust. Administrative, methodological, and technical support: Veronica Silva Dunning (trial administrator), lan Russell (co-applicant), Helen Stanton, Tim Harris, Cathy Lisles, Neil Burt, Fasih Alam, Benedict Hodge, Karen Marsh (consultation rater), Nina Gobat (consultation rater), Carolyn Blake, and members of the administrative team at SEWTU. Members of the trial steering committee: Steve Greene (chair), Julie Edge, Tim Peters, Frank Snoek. Members of the Stakeholder Advisory Group: the young patients, parents, adult patients, and diabetes professionals participating in the SAG who critically helped design the trial intervention and Neil Frude who acted as SAG facilitator. User representative: We particularly thank the dedicated input of our parent and patient representative Charlotte Crawley (co-applicant) in particular during the development phase of the study. Other contributors to programme development: students and staff at Whitchurch High School (drama club), escape to Design (3T: TimeToTalk), the HealthCare Learning Company (Talking Diabetes online learning programme, in particular Pat Cannon, Valerie Dougall), Philippa Thomas and Dafydd Gape (learning programme actors). Institutional support: the South East Wales Trials Unit is funded by the Wales Assembly Government through the National Institute of Social Care and Health Research and the authors thank SEWTU's contribution to study implementation.

Contributors: JWG and MR were coprincipal investigators and joint guarantors of the study in its entirety. JWG, MR, KeH, KB, SC, DC, EC, $\mathrm{HH}, \mathrm{KaH}, \mathrm{ML}, \mathrm{LL}, \mathrm{RP}, \mathrm{SR}, \mathrm{CCB}$, and RMcN were responsible for developing the research question and study design and implementation of the study protocol. RMcN was responsible for trial management. RP led the main statistical analysis. TP led the analysis of consultation ratings. MR and JWG were responsible for drafting the manuscript. All those listed as authors were responsible for reading, commenting on, and approving the final manuscript. All contributors were independent from the study funders in conducting the research.

Funding: The UK National Institute for Health Research Health Technology Assessment Programme funded the intervention development and trial phases. An educational grant from Novo Nordisk UK partially funded the production of some study materials. This study was sponsored by Cardiff University.

Competing interests: All authors have completed the ICMJE uniform disclosure form at www.icmje.org/coi_disclosure.pdf (available on request from the corresponding author) and declare: all authors had financial support from the National Institute for Health Research Health Technology Assessment research funding scheme for the submitted work; no financial relationships with any organisations that might have an interest in the submitted work in the previous three years; no other relationships or activities that could appear to have influenced the submitted work.

Ethical approval: The intervention development phase was approved by the South East Wales NHS research ethics committee. The trial phase was approved by the Thames Valley NHS (now South Central-Berkshire) research ethics committee (07/MRE12/9). Approval for the conduct of the study at each participating centre was provided through the corresponding NHS organisation (NHS R\&D approval).

Data sharing: No additional data available.

1 Metcalfe MA, Baum JD. Incidence of insulin dependent diabetes in children aged under 15 years in the British Isles during 1988. BMJ 1991:302:960-1.

Patterson C, Dahlquist G, Gyürüs E, Green A, Soltész G, EURODIAB Study Group. Incidence trends for childhood type 1 diabetes in Europe during 1989-2003 and predicted new cases 2005-20: a multicentre prospective registration study. Lancet 2009;373:2027-33.

3 Diabetes Control and Complications Trial Research Group. The effect of intensive treatment of diabetes on the development and progression of long-term complications in insulin-dependent diabetes mellitus. The Diabetes Control and Complications Trial Research Group. N Engl J Med 1993;329:977-86.

4 La Greca A, Follansbee D, Skyler J. Developmental and behavioral aspects of diabetes management in youngsters. J Child Health Care 1990;24:239-44.

5 National Institute for Clinical Excellence. Type 1 diabetes: diagnosis and management of type 1 diabetes in children, young people and adults. NICE, 2004.

6 Diabetes UK. The National Paediatric Diabetes Audit: results from the audit year 2002. Diabetes UK, 2004 


\section{What is already known on this topic}

Psychoeducational interventions can lead to improvements in blood glucose control in teenagers with diabetes when delivered by specialist practitioners, but this has limited reach among the wide range of patients attending clinics

Training whole care teams in psychoeducational consultation skills may increase the reach of enhanced psychoeducational consulting skills, but there is an absence of evidence for effectiveness

\section{What this study adds}

Members of a multidisciplinary specialist paediatric diabetes team can be trained to modify their consultations to incorporate a rigorously developed behaviour change approach

Such an approach in a routine UK National Health Service clinic setting, however, did not lead to improvements in metabolic control of young people

7 Hampson SE, Skinner TC, Hart J, Storey L, Gage H, Foxcroft D, et al. Effects of educational and psychosocial interventions for adolescents with diabetes mellitus: a systematic review. Health Technol Assess 2001:5:1-79.

8 Murphy HR, Rayman G, Skinner TC. Psycho-educational interventions for children and young people with type 1 diabetes. Diabet Med 2006;23:935-43.

9 Channon SJ, Huws-Thomas MV, Rollnick S, Hood K, Cannings-John RL, Rogers C, et al. A multicenter randomized controlled trial of motivational interviewing in teenagers with diabetes. Diabetes Care 2007;30:1390-5.

10 Satin W, La Greca AM, Zigo MA, Skyler JS. Diabetes in adolescence: effects of multifamily group intervention and parent simulation of diabetes. $J$ Pediatr Psychol 1989;14:259-75.

11 Channon S, Smith VJ, Gregory JW. A pilot study of motivational interviewing in adolescents with diabetes. Arch Dis Child 2003;88:680-3.

12 Northam EA, Todd S, Cameron FJ. Interventions to promote optimal health outcomes in children with type 1 diabetes-are they effective? Diabet Med 2006;23:113-21.

13 Gosden C, Edge J, Holt R, James J, Turner B, Winocour P, et al. The fifth UK paediatric diabetes services survey: meeting guidelines and recommendations? Arch Disease Child 2010:95:837-40.

14 Medical Research Council. Developing and evaluating complex interventions: new guidance. MRC, 2008.

15 Hambly H, Robling M, Crowne E, Hood K, Gregory JW. Communication skills of healthcare professionals in paediatric diabetes services. Diabet Med 2009;26:502-9.

16 Channon S, Hambly H, Robling M, Bennert K, Gregory JW, the DEPICTED Study Team. Meeting the psychosocial needs of children with diabetes within routine clinical practice. Diabetic Med 2010;27:1209-11.

17 Hawthorne K, Bennert K, Lowes L, Channon S, Robling M, Gregory JW, et al. Incorporating the experiences of children with diabetes and their parents in the development of communication skills training (the DEPICTED Study) for health-care staff in paediatric diabetes services. Diabetic Med 2011;28:1103-8.

18 Lowes L, Robling M, Bennert K, Crawley C, Hambly H, Hawthorne K, et al. Involving lay and professional stakeholders in the development of a research intervention for the DEPICTED Study. Health Expect 2010;14:250-60.

19 McNamara R, Robling M, Hood K, Bennert K, Channon S, Cohen D, et al. Development and Evaluation of a Psychosocial Intervention for Children and Teenagers Experiencing Diabetes (DEPICTED): a protocol for a cluster randomised controlled trial of the effectiveness of a communication skills training programme for healthcare professionals working with young people with type 1 diabetes. BMC Health Serv Res 2010;10:36.

20 Gregory JW, Robling M, Bennert K, Channon S, Cohen D, Crowne E, et al. Developmen and evaluation by a cluster randomised trial of a psychosocial intervention in children and teenagers experiencing diabetes: the DEPICTED study. Health Technol Assess 2011;15:1-202.

21 Carter BR, Hood K. Balance algorithm for cluster randomized trials. BMC Med Res Methodol 2008;8:65.

22 Rabb G, Butcher I. Balance in cluster randomized trials. Stat Med 2001;20:351-65

23 Rollnick S, Butler CC, McCambridge J, Kinnersley P, Elwyn G, Resnicow K. Consultations about changing behaviour. BMJ 2005;331:961-3.

24 Miller W, Rollnick S. Motivational interviewing: preparing people for change. 2nd ed. Guilford Press, 2002
25 Varni JW, Burwinkle TM, Jacobs JR, Gottschalk M, Kaufman F, Jones K. Reliability and validity of the Pediatric Quality of Life Inventory Generic Score Scales and Type 1 Diabetes Module. Diabetes Care 2003;18:631-7.

26 Polonsky WH, Anderson BJ, Lohrer PA, Welch G, Jacobson AM, Aponte JE, et al. Assessment of diabetes-related distress. Diabetes Care 1995;18:754-60.

27 Howie JG, Heaney DJ, Maxwell M, Walker JJ. A comparison of a Patient Enablement Instrument (PEI) against two established satisfaction scales as an outcome measure of primary care consultations. Fam Pract 1998;15:165-71.

28 Williams GC, Freedman ZR, Deci EL. Supporting autonomy to motivate patients with diabetes for glucose control. Diabetes Care 1998;21:1644-51.

29 Dolovich LR, Nair KM, Ciliska DK, Lee HN, Birch S, Gafni A, et al. The Diabetes Continuity of Care Scale: the development and initial evaluation of a questionnaire that measures continuity of care from the patient perspective. Health Soc Care Community 2004;12:475-87.

30 Weissberg-Benchell J, Glasgow AM, Tynan WD, Wirtz P, Turek J, Ward J. Adolescent diabetes management and mismanagement. Diabetes Care 1995;18:77-82.

31 Rollnick S, Mason P, Butler C. Health behaviour change: a guide for practitioners . Churchill Livingstone, 1999.

32 Moyers TB, Martin T, Manuel JK, Hendrickson SML, Miller WR. Assessing competence in the use of motivational interviewing. J Subst Abuse Treat 2005;28:19-26.

33 Rollnick S, Butler CC, Kinnersley P, Gregory J, Mash B. Motivational interviewing. BMJ 2010;340:c1900.

34 Ismail K, Maissi E, Thomas S, Chalder T, Schmidt U, Bartlett J, et al. A randomised controlled trial of cognitive behaviour therapy and motivational interviewing for people with type 1 diabetes mellitus with persistent sub-optimal glycaemic control: a Diabete and Psychological Therapies (ADaPT) study. Health Technol Assess 2010;14:1-101.

35 Laffel L, Vangsness L, Connell A, Goebel-Fabbri A, Butler D, Anderson B. Impact of ambulatory, family-focused teamwork intervention on glycemic control in youth with type 1 diabetes. J Pediatr 2003;142:409-16.

36 Winkley K, Ismail K, Landau S, Eisler I. Psychological interventions to improve glycaemic control in patients with type 1 diabetes: systematic review and meta-analysis of randomised controlled trials. BMJ 2006;333:65

37 Jefferson IG, Swift PG, Skinner TC, Hood GK. Diabetes services in the UK: third national survey confirms continuing deficiencies. Arch Dis Child 2003;88:53-6.

Accepted: 2 March 2012

\section{Cite this as: BMJ 2012;344:e2359}

This is an open-access article distributed under the terms of the Creative Commons Attribution Non-commercial License, which permits use, distribution, and reproduction in any medium, provided the original work is properly cited, the use is non commercial and is otherwise in compliance with the license. See: http://creativecommons.org/licenses/by$\mathrm{nc} / 2.0 /$ and http://creativecommons.org/licenses/by-nc/2.0/legalcode. 


\section{Tables}

\begin{tabular}{|c|c|c|c|}
\hline Characteristics & Standard care & Training programme & Overall \\
\hline \multicolumn{4}{|l|}{ Children } \\
\hline Mean (SD) $\mathrm{HbA}_{1 \mathrm{c}}$ level (\%) & $9.2(1.8)(n=333)$ & $9.4(1.7)(n=356)$ & $9.3(1.8)(n=689)$ \\
\hline \multicolumn{4}{|l|}{$\mathrm{HbA}_{1 \mathrm{c}}$ distribution: } \\
\hline$<7.5 \%$ & $43(13)$ & $33(9)$ & $76(11)$ \\
\hline $7.5-9 \%$ & $123(37)$ & $117(33)$ & $240(35)$ \\
\hline$>9 \%$ & $167(50)$ & $206(58)$ & $373(54)$ \\
\hline Mean (SD) age (years) & $10.7(2.8)(n=334)$ & $10.4(2.8)(n=359)$ & $10.6(2.8)$ \\
\hline Mean (SD) age (years) at diagnosis & $6.3(3.0)(n=253)$ & $5.7(3.0)(n=255)$ & $6.0(3.0)$ \\
\hline Mean (SD) duration (years) of diabetes & $5.0(2.7)(n=253)$ & $5.2(2.8)(n=255)$ & $5.1(2.7)$ \\
\hline Boys & $155(46)$ & $187(52)$ & $342(49)$ \\
\hline Mean (SD) body mass index & $19.2(3.1)(n=329)$ & $19.5(3.2)(n=356)$ & $19.4(3.2)$ \\
\hline \multicolumn{4}{|l|}{ Ethnicity: } \\
\hline White British & 259 (91) & $262(91)$ & $521(91)$ \\
\hline Other white & $7(2)$ & $5(2)$ & $12(2)$ \\
\hline Mixed & $11(4)$ & $12(4)$ & $23(4)$ \\
\hline Black or black British & $1(<1)$ & $4(1)$ & $5(1)$ \\
\hline Asian or Asian British & $7(2)$ & $6(2)$ & $13(2)$ \\
\hline Other & $1(<1)$ & $0(0)$ & $1(<1)$ \\
\hline \multicolumn{4}{|l|}{ Carer providing data } \\
\hline Carer status: mothers & $286(93)$ & $286(93)$ & $572(93)$ \\
\hline Usually attends clinic & $284(99)$ & $286(99)$ & 570 (99) \\
\hline Provide majority of care & $284(97)$ & $281(99)$ & 565 (98) \\
\hline Generally see same doctor at clinic & $286(71)$ & $286(69)$ & $572(70)$ \\
\hline Generally see same nurse at clinic & $285(89)$ & $284(93)$ & $569(91)$ \\
\hline \multicolumn{4}{|l|}{ Socioeconomic class: } \\
\hline Managerial and professional occupations & $139(54)$ & $134(54)$ & $273(57)$ \\
\hline Immediate occupations & $31(12)$ & $38(15)$ & $69(14)$ \\
\hline Small employers and own account workers & $26(10)$ & $23(9)$ & $49(10)$ \\
\hline Lower supervisory and technical occupations & $22(9)$ & $28(11)$ & $50(10)$ \\
\hline Semiroutine and routine occupations & $40(16)$ & $27(11)$ & $67(13)$ \\
\hline
\end{tabular}

Denominators vary owing to missing values (assumed to be missing at random). 
Table 2/ Secondary outcomes for young people with type 1 diabetes according to allocation group. Values are means (standard deviations) unless stated otherwise

\begin{tabular}{|c|c|c|c|c|c|c|c|c|c|}
\hline \multirow[b]{2}{*}{ Variables } & \multicolumn{3}{|c|}{ Standard care } & \multirow[b]{2}{*}{ No } & \multicolumn{2}{|c|}{ Training programme } & \multicolumn{3}{|c|}{ Adjusted for baseline score } \\
\hline & No & Baseline & Follow-up & & Baseline & Follow-up & ICC (\%) & Intervention effect $(95 \% \mathrm{Cl})$ & $P$ value \\
\hline Healthcare climate & 182 & $4.1(0.60)$ & $4.0(0.62)$ & 164 & $4.0(0.69)$ & $4.0(0.71)$ & 10.1 & $0.04(-0.2$ to 0.2$)$ & 0.66 \\
\hline \multicolumn{10}{|l|}{ Quality of life: } \\
\hline Barriers & 186 & $69.3(19.6)$ & $73.3(18.2)$ & 167 & $66.8(22.0)$ & $67.5(21.2)$ & 0.9 & $-4.6(-8.5$ to -0.6$)$ & 0.03 \\
\hline Symptoms & 185 & $56.5(13.6)$ & $57.2(14.3)$ & 167 & $54.4(15.0)$ & $55.3(15.3)$ & 3.3 & $-0.9(-4.2$ to 2.4$)$ & 0.60 \\
\hline Adherence & 183 & $77.9(15.1)$ & $80.6(15.4)$ & 166 & $76.4(17.2)$ & $76.8(17.4)$ & 0 & $-3.1(-6.3$ to -0.01$)$ & 0.05 \\
\hline Worry & 181 & $67.3(22.0)$ & $69.8(20.2)$ & 162 & $68.8(23.8)$ & $67.2(23.2)$ & 0 & $-3.4(-7.4$ to 0.7$)$ & 0.10 \\
\hline Communication & 181 & $66.0(23.8)$ & $69.1(22.2)$ & 162 & $63.3(26.9)$ & $62.3(26.9)$ & 0.1 & $-5.4(-11.1$ to 0.3$)$ & 0.06 \\
\hline $\begin{array}{l}\text { Diabetes continuity in } \\
\text { care }\end{array}$ & 121 & $4.5(0.52)$ & $4.3(0.66)$ & 88 & $4.3(0.72)$ & $4.2(0.76)$ & 7.8 & $-0.02(-0.3$ to 0.2$)$ & 0.85 \\
\hline $\begin{array}{l}\text { Problem areas in } \\
\text { diabetes }\end{array}$ & 123 & $33.6(19.2)$ & $36.4(20.6)$ & 89 & $35.0(21.7)$ & $38.9(20.8)$ & 0 & $1.8(-3.0$ to 6.6$)$ & 0.46 \\
\hline Importance & 123 & $4.2(0.66)$ & $4.0(0.67)$ & 89 & $4.1(0.62)$ & $4.0(0.69)$ & 0 & $0.2(-0.13$ to 0.17$)$ & 0.81 \\
\hline Confidence & 123 & $3.7(0.73)$ & $3.7(0.72)$ & 89 & $3.7(0.70)$ & $3.5(0.77)$ & 0 & $-0.2(-0.4$ to 0$)$ & 0.06 \\
\hline Care/mismanagement & 110 & $1.6(0.53)$ & $1.8(0.66)$ & 80 & $1.6(0.46)$ & $1.8(0.60)$ & 0 & $0.03(-0.12$ to 0.18$)$ & 0.72 \\
\hline \multicolumn{10}{|l|}{ Patient enablement: } \\
\hline Interim & 116 & $28.0(28.8)$ & $19.7(25.4)$ & 83 & $28.5(30.4)$ & $30.1(32.6)$ & 6.4 & $10.4(0.5$ to 20.4$)$ & 0.04 \\
\hline 12 months & 122 & $29.1(30.9)$ & $26.4(30.9)$ & 88 & $28.4(29.4)$ & $21.3(27.7)$ & 9.0 & $-5.2(-16.1$ to 5.7$)$ & 0.34 \\
\hline
\end{tabular}

ICC=intraclass correlation coefficient. 
Table 3| Secondary outcomes for young people with type 1 diabetes according to allocation group. Values are numbers (percentages) unless stated otherwise

\begin{tabular}{|c|c|c|c|c|c|c|c|c|c|}
\hline \multirow[b]{2}{*}{ Individual item scores } & \multirow[b]{2}{*}{ No } & \multicolumn{2}{|c|}{ Standard care } & \multirow[b]{2}{*}{ No } & \multicolumn{2}{|c|}{ Training programme } & \multicolumn{2}{|c|}{$\begin{array}{c}\text { Adjusted for baseline (reference group=standard } \\
\text { care) }\end{array}$} & \multirow[b]{2}{*}{$P$ value } \\
\hline & & Baseline & Follow-up & & Baseline & Follow-up & ICC (\%) & Odds ratio $(95 \% \mathrm{Cl})$ & \\
\hline Check glucose $>4$ times a day & 118 & $62(51)$ & $61(52)$ & 84 & $40(48)$ & $36(43)$ & 0 & 0.7 (0.39 to 1.32$)$ & 0.29 \\
\hline \multicolumn{10}{|l|}{ Experiencing emotion items ${ }^{*}:$} \\
\hline Fed up & 179 & $62(35)$ & $70(39)$ & 163 & $55(34)$ & $779(47)$ & 1.0 & 1.5 (0.95 to 2.42$)$ & 0.08 \\
\hline Excited & 180 & $59(33)$ & $42(23)$ & 161 & $64(40)$ & $54(34)$ & 0.5 & $1.6(0.93$ to 2.65$)$ & 0.09 \\
\hline Guilty & 177 & $23(13)$ & $16(9)$ & 161 & $16(10)$ & $20(12)$ & 0 & $1.6(0.79$ to 3.41$)$ & 0.18 \\
\hline Good & 181 & $130(72)$ & $115(64)$ & 162 & $108(67)$ & $104(64)$ & 0 & 1.1 (0.71 to 1.86$)$ & 0.57 \\
\hline Worried & 179 & $61(34)$ & $47(26)$ & 165 & $64(39)$ & $56(34)$ & 6.4 & 1.4 (0.85 to 2.29$)$ & 0.19 \\
\hline Living with diabetest: & 183 & $99(54)$ & $93(51)$ & 159 & $85(54)$ & $83(52)$ & 0 & $1.07(0.69$ to 1.66$)$ & 0.77 \\
\hline General quality of life $\neq$ & 181 & $135(75)$ & $134(74)$ & 161 & $107(67)$ & $106(66)$ & 0 & 0.74 (0.45 to 1.22$)$ & 0.24 \\
\hline $\begin{array}{l}\text { Quality of life compared with last } \\
\text { year§ }\end{array}$ & 180 & $85(47)$ & $83(46)$ & 163 & $70(43)$ & $72(44)$ & 0 & $0.96(0.62$ to 1.48$)$ & 0.84 \\
\hline
\end{tabular}

ICC=intraclass correlation coefficient.

*Reported "a little," "quite a bit," or "very much" in response to emotion item.

†Reported "much easier" or "easier" living with diabetes compared with last year.

†Reported in general feeling "very happy" or "happy."

§Reported being "happier" or "much happier" than last year. 
Table 4| Secondary outcomes for carers of young people with type 1 diabetes according to allocation group. Values are means (standard deviations) unless stated otherwise

\begin{tabular}{|c|c|c|c|c|c|c|c|c|c|}
\hline \multirow[b]{2}{*}{ Variables } & \multirow[b]{2}{*}{ No } & \multicolumn{2}{|c|}{ Standard care } & \multirow[b]{2}{*}{ No } & \multicolumn{2}{|c|}{ Training programme } & \multicolumn{2}{|c|}{ Adjusted for baseline score } & \multirow[b]{2}{*}{$P$ value } \\
\hline & & Baseline & Follow-up & & Baseline & Follow-up & ICC (\%) & Effect $(95 \% \mathrm{Cl})$ & \\
\hline Healthcare climate & 209 & $4.3(0.57)$ & $4.2(0.59)$ & 202 & $4.2(0.64)$ & $4.3(0.62)$ & 3.0 & 0.1 (0 to 0.2$)$ & 0.13 \\
\hline \multicolumn{10}{|l|}{ Quality of life: } \\
\hline Barriers & 208 & $61.3(17.5)$ & $62.3(17.5)$ & 203 & $60.4(18.7)$ & $59.0(20.2)$ & 0 & $-2.9(-6.1$ to 0.4$)$ & 0.08 \\
\hline Symptoms & 209 & $58.9(13.3)$ & $60.0(13.6)$ & 202 & $56.1(13.9)$ & $57.1(14.9)$ & 0 & $-1.0(-3.1$ to 1.1$)$ & 0.36 \\
\hline Adherence & 208 & $74.9(16.3)$ & $75.0(15.9)$ & 203 & $73.9(16.4)$ & $73.2(17.3)$ & 0.6 & $-1.4(-4.4$ to 1.6$)$ & 0.35 \\
\hline Worry & 205 & $54.6(20.8)$ & $52.9(22.2)$ & 201 & $50.9(24.1)$ & $51.9(21.9)$ & 0 & $0.8(-2.9$ to 4.6$)$ & 0.67 \\
\hline Communication & 204 & $66.8(26.8)$ & $67.7(25.3)$ & 199 & $63.7(28.0)$ & $64.4(29.0)$ & 0 & $-1.7(-6.2$ to 2.8$)$ & 0.46 \\
\hline $\begin{array}{l}\text { Diabetes continuity of } \\
\text { care }\end{array}$ & 208 & $4.4(0.59)$ & $4.2(0.73)$ & 203 & $4.3(0.69)$ & $4.4(0.63)$ & 0 & 0.2 (0.1 to 0.3$)$ & 0.01 \\
\hline $\begin{array}{l}\text { Problem areas in } \\
\text { diabetes }\end{array}$ & 209 & $41.4(17.6)$ & $43.0(19.4)$ & 203 & $45.6(18.7)$ & $45.2(20.2)$ & 3.0 & $-0.9(-3.7$ to 2.0$)$ & 0.55 \\
\hline Importance & 208 & $4.7(0.42)$ & $4.7(0.40)$ & 202 & $4.6(0.41)$ & $4.7(0.41)$ & 0 & $0.02(-0.1$ to 0.1$)$ & 0.61 \\
\hline Confidence & 208 & $3.7(0.66)$ & $3.8(0.76)$ & 203 & $3.7(0.74)$ & $3.8(0.73)$ & 0 & $-0.02(-0.1$ to 0.1$)$ & 0.78 \\
\hline Care/mismanagement & 186 & $1.5(0.43)$ & $1.6(0.57)$ & 183 & $1.5(0.47)$ & $1.6(0.51)$ & 0 & $-0.01(-0.10$ to 0.09$)$ & 0.87 \\
\hline \multicolumn{10}{|l|}{ Enablement: } \\
\hline Interim & 209 & $18.3(27.8)$ & $16.3(25.2)$ & 190 & $25.1(31.5)$ & $23.5(28.4)$ & 3.0 & $5.2(-1.3$ to 11.6$)$ & 0.11 \\
\hline 12 months & 207 & $22.3(29.7)$ & $23.9(32.1)$ & 201 & $24.3(32.5)$ & $28.7(35.4)$ & 3.4 & $4.4(-3.5$ to 12.3$)$ & 0.27 \\
\hline
\end{tabular}

ICC=intraclass correlation coefficient. 
Table 5 | Secondary outcomes for carers of young people with type 1 diabetes according to allocation group. Values are numbers (percentages) unless stated otherwise

\begin{tabular}{|c|c|c|c|c|c|c|c|c|c|}
\hline \multirow[b]{2}{*}{ Individual item scores } & \multirow[b]{2}{*}{ No } & \multicolumn{2}{|c|}{ Standard care } & \multirow[b]{2}{*}{ No } & \multicolumn{2}{|c|}{ Training programme } & \multicolumn{2}{|c|}{ (Reference group=control) } & \multirow[b]{2}{*}{$P$ value } \\
\hline & & Baseline & Follow-up & & Baseline & Follow-up & $\operatorname{ICC}(\%)$ & Odds ratio $(95 \% \mathrm{Cl})$ & \\
\hline Check glucose $>4$ times a day & 202 & $132(65)$ & $129(64)$ & 191 & $104(55)$ & $103(54)$ & 1.5 & 0.25 (0.16 to 1.37$)$ & 0.37 \\
\hline \multicolumn{10}{|l|}{ Experiencing emotion items*: } \\
\hline Fed up & 200 & $55(28)$ & $59(30)$ & 195 & $51(26)$ & $60(31)$ & 0 & $1.13(0.69$ to 1.85$)$ & 0.63 \\
\hline Excited & 196 & $30(15)$ & $23(12)$ & 190 & $30(16)$ & $37(20)$ & 3.3 & 1.90 (1.05 to 3.43$)$ & 0.03 \\
\hline Guilty & 198 & $49(25)$ & $55(28)$ & 190 & $49(26)$ & $57(30)$ & 0 & $1.11(0.68$ to 1.83$)$ & 0.67 \\
\hline Good & 200 & $132(66)$ & $120(60)$ & 191 & $133(70)$ & $124(65)$ & 2.7 & $1.19(0.76$ to 1.85$)$ & 0.44 \\
\hline Worried & 200 & $98(49)$ & $103(52)$ & 193 & $101(52)$ & $108(56)$ & 0 & $1.16(0.75$ to 1.79$)$ & 0.50 \\
\hline Living with diabetes† & 206 & $77(37)$ & $63(31)$ & 201 & $71(35)$ & $61(30)$ & 1.2 & $0.91(0.57$ to 1.45$)$ & 0.69 \\
\hline General quality of life & 207 & $126(61)$ & $121(59)$ & 197 & $130(66)$ & $104(53)$ & 1.4 & $0.65(0.41$ to 1.03$)$ & 0.06 \\
\hline Quality of life compared with last year§ & 207 & $51(25)$ & $51(25)$ & 198 & $66(33)$ & $49(25)$ & 2.4 & 1.01 (0.66 to 1.55$)$ & 0.97 \\
\hline
\end{tabular}

ICC=intraclass correlation coefficient.

*Reported "a little," "quite a bit," or "very much" in response to emotion item.

†Reported "much easier" or "easier" living with diabetes compared with last year.

‡Reported in general feeling "very happy" or "happy."

$\S$ Reported being "happier" or "much happier." 
Table 6 | Guiding style scores in intervention and control group at various time points. Values are means (standard deviations), medians, unless stated otherwise

\begin{tabular}{|c|c|c|c|c|c|}
\hline \multirow[b]{2}{*}{ Scale } & \multicolumn{2}{|c|}{ Training programme } & \multirow{2}{*}{$\begin{array}{l}\text { Standard care } \\
\text { Before training at end } \\
\text { of one year }(n=29)\end{array}$} & \multicolumn{2}{|c|}{ Difference in means ( $P$ value ${ }^{\star}$ ) } \\
\hline & $\begin{array}{l}\text { Immediately after } \\
\text { training }(n=28)\end{array}$ & $\begin{array}{l}\text { One year after } \\
\text { training }(n=29)\end{array}$ & & $\begin{array}{c}\text { One year after } \\
\text { training-immediately after } \\
\text { training }\end{array}$ & $\begin{array}{l}\text { One year after } \\
\text { training-before training }\end{array}$ \\
\hline Guiding style & $2.6(0.91), 3$ & $2.3(0.85), 2$ & $1.2(0.47), 1$ & $-0.33(0.128)$ & $1.14(<0.001)$ \\
\hline Evocation & $2.6(1.06), 3$ & 2.0 (1.02), 2 & $1.1(0.44), 1$ & $-0.61(0.039)$ & $0.90(<0.001)$ \\
\hline Collaboration & 2.6 (0.92), 3 & $2.3(0.84), 2$ & $1.5(0.63), 1$ & $-0.30(0.188)$ & $0.83(<0.001)$ \\
\hline Autonomy-supportive & $2.6(0.83), 3$ & $2.4(0.82), 3$ & $1.3(0.60), 1$ & $-0.26(0.171)$ & $1.07(<0.001)$ \\
\hline
\end{tabular}

*Mann-Whitney U test. 
Table $7 \mid$ Proportion of control and intervention groups with task done or partially done at one year. Values are numbers (percentages) unless stated otherwise

\begin{tabular}{|c|c|c|c|c|c|}
\hline \multirow[b]{2}{*}{ Task } & \multicolumn{2}{|c|}{ Training programme } & \multirow{2}{*}{$\begin{array}{l}\text { Standard care } \\
\text { Before training at end } \\
\text { of one year }(n=29)\end{array}$} & \multicolumn{2}{|c|}{ Difference in proportions $(95 \% \mathrm{Cl})$} \\
\hline & $\begin{array}{l}\text { Immediately after } \\
\text { training }(\mathbf{n = 2 8})\end{array}$ & $\begin{array}{l}\text { One year after } \\
\text { training }(n=29)\end{array}$ & & $\begin{array}{c}\text { One year after } \\
\text { training-immediately after } \\
\text { training }\end{array}$ & $\begin{array}{l}\text { One year after training-before } \\
\text { training at end of one year }\end{array}$ \\
\hline $\begin{array}{l}\text { Shared agenda } \\
\text { setting }\end{array}$ & $20(71.4)$ & $15(51.7)$ & $2(6.9)$ & $-0.20(-0.42$ to 0.05$)$ & $0.45(0.22$ to 0.62$)$ \\
\hline Pros and cons & $8(28.6)$ & $3(10.3)$ & $0(0.0)$ & $-0.18(-0.38$ to 0.03$)$ & $0.10(-0.03$ to 0.26$)$ \\
\hline $\begin{array}{l}\text { Importance and } \\
\text { confidence }\end{array}$ & $6(21.4)$ & $3(10.3)$ & $0(0.0)$ & $-0.11(-0.30$ to 0.08$)$ & $0.10(-0.03$ to 0.26$)$ \\
\hline Brainstorming & $16(57.1)$ & $7(24.1)$ & $1(3.5)$ & $-0.33(-0.53$ to -0.08$)$ & $0.21(0.03$ to 0.39$)$ \\
\hline
\end{tabular}


Table 8| Skilfulness scores in intervention group practitioners immediately after training and at one year after training. Values are means (standard deviations), medians, unless stated otherwise

\section{Training programme}

Skilfulness

No Immediately after training No One year after training

Shared agenda setting

20

Pros and cons 8

Importance and confidence

Brainstorming

$16 \quad 2.2(1.17)$

$2.5(0.89), 2$

$152.3(0.80), 2$

$1.7(0.58), 2$

$31.7(0.58), 2$

$2.6(0.54), 3$

Difference in means (one year after training-immediately after training) ( $P$ value $\left.{ }^{\star}\right)$

*Mann-Whitney U test. 


\section{Figure}

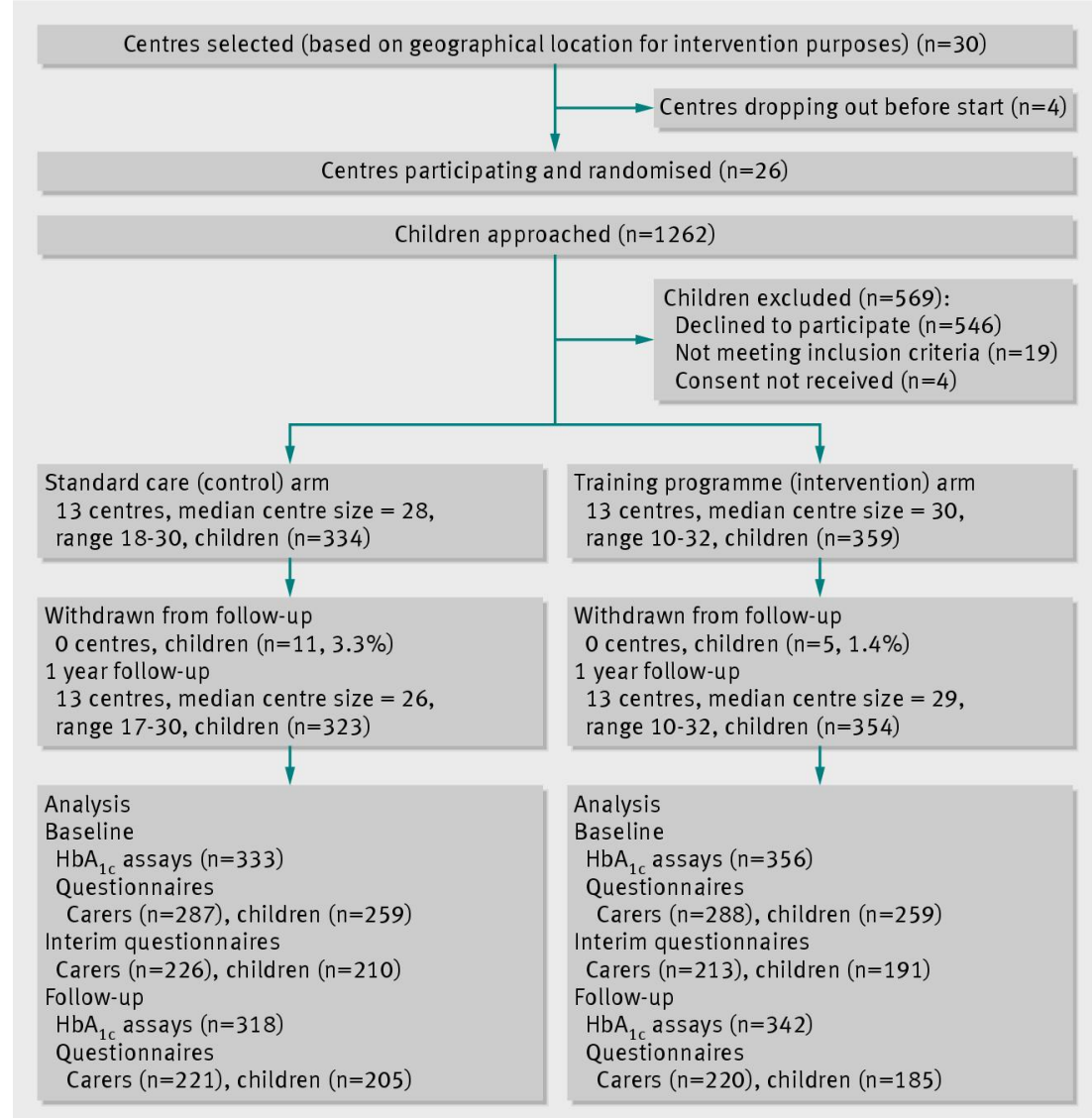

Flow of participants through study 